\title{
PENGARUH FASILITAS KAMAR TERHADAP KEPUASAN TAMU MENGINAP DI BASKO HOTEL PADANG
}

\author{
Ferdian Sandy Putra, Ira Meirina Chair \\ Program Studi D4 Manajemen Perhotelan \\ Fakultas Pariwisata dan Perhotelan Universitas Negeri Padang \\ email: ferdiansandi22@gmail.com
}

\begin{abstract}
This research was carried out because there were guests who were not satisfied with the room facilities at the Basko Hotel Padang. This study was conducted to determine the effect of room facilities on guest satisfaction in Basko Hotel Padang. This research is a quantitative descriptive type with a casual associative method with the aim to find out how much influence the room facilities have on guest satisfaction at Basko Hotel Padang. The population in Basko Hotel Padang is 4829 people (per month). There are a number of samples in this study of 100 people using purposive sampling taking technique. The technique of data collection is done by distributing questionnaires using a likert scale that has been tested for validity and reliability. The analysis technique used is a simple linear regression test and a deterence coefficient test carried out through the SPSS version 16.00 computer program. After doing research the results are as follows: (1) Room Facilities are in the less good category (49\%), (2) guest satisfaction is included in the less good category (56\%), (3) Obtained the coefficient of 0.765 with the value of t count 7.678 on sig. $0,00<0,05$. So each increase of 1 unit variable room fasilities can increase 0,765 guest satisfaction units. The effect of room facilities variables on guest satisfaction is 37,6\%, the remaining $61,3 \%$ is influenced by other factors.
\end{abstract}

\section{Keywords: Room Facilities, Guest Satisfaction}

\section{PENDAHULUAN}

Indonesia sebagai salah satu tujuan wisata dikawasan Asia pasifik memiliki potensi cukup besar dalam kepariwisataan, baik potensi fisik maupun potensi sosial budaya yang merupakan modal besar bagi pengembangan pariwisata. Salah satu sektor pendukung usaha pariwisata adalah jasa perhotelan. Menurut pendapat Rumekso (2001: 2), "Hotel adalah bentuk bangunan yang menyediakan kamar - kamar untuk menginap para tamu, makanan dan minuman serta fasilitas- fasilitas lain yang diperlukan dan dikelola secara profesional untuk mendapatkan keuntungan". Sulastiyono (2011 : 15) mengatakan "Hotel adalah suatu perusahaan yang dikelola oleh pemiliknya dengan menyediakan pelayanan makanan, minuman, dan fasilitas kamar untuk tidur kepada orang- orang yang melakukan perjalanan dan mampu membayar dengan jumlah yang wajar sesuai dengan pelayanan yang diterima tanpa ada perjanjian khusus". Didalam industri perhotelan harus bisa bersikap lebih kreatif supaya bisa menarik perhatian para pelanggan sehingga dapat menciptakan kepuasan tamu yang maksimal.

Menurut pendapat Setiawati (2009: 12) "Kepuasan pelanggan adalah suatu tingkatan dimana kebutuhan, keinginan dan harapan dari pelanggan dapat terpenuhi yang akan mengakibatkan terjadinya pembelian ulang atau kesetiaan yang berlanjut".

Tingkat kepuasan pelanggan begitu penting untuk menentukan tingkat keberhasilan sebuah hotel. Salah satu hal yang akan menjadi bahan pertimbangan tamu untuk memilih tempat menginap yaitu fasilitas yang 


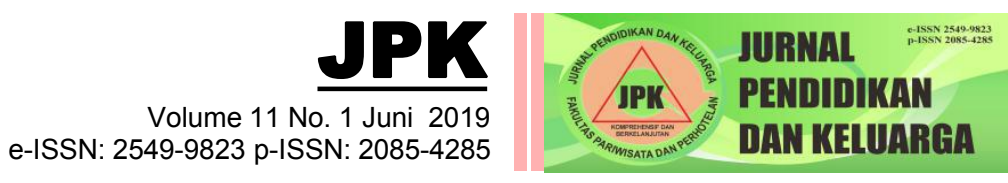

ada di hotel. Sulastiyono (2011: 28) berpendapat, "Fasilitas adalah penyediaan perlengkapan-perlengkapan fisik untuk memberikan kemudahan kepada para tamu dalam melaksanakan aktivitas-aktivitas atau kegiatan-kegiatan, sehingga kebutuhan tamu dapat terpenuhi selama di hotel".

Semua hotel harus memperhatikan dan meingkatkan fasilitas-fasilitas yang dimiliki, termesuk juga hotel,-hotel yang berada di kota Padang. Basko Hotel Padang yang dipimpin oleh pimpinan perusahaan Basko Grup, H. Basrizal Koto yang menempati lokasi lokasi strategis di pintu gerbang kota Padang. Sebagai salah satu hotel berbintang, Basko Hotel membidik semua segmen pasar, yaitu segmen pemerintah, travel, perusahaan, dan perorangan.

Salah satu bahan pertimbangan tamu untuk menentukan pilihan adalah fasilitas. Apabila fasilitas yang disediakan pihak hotel semakin lengkap dan menarik, maka akan tercapainya harapan tamu dan akan ada keinginan untuk menginap kembali ke hotel. Namun terdapat komentar negatif di situs online (Traveloka, Agoda, dan TripAdvisor) tentang Basko Hotel Padang, pada tahun 2017 terdapat beberapa keinginan tamu belum terpenuhi dengan baik. Seingga harapan tamu tidak terpenuhi dengan baik, hal ini akan membuat tamu tidak puas dengan fasilitas kamar yang ada. Komentar negatif tersebut adalah AC tidak berfungsi, sehingga udara di dalam kamar terasa cukup panas. Keluhan terhadap warna handuk yang sudah kumal kelihatan tidak bersih, lantai kamar yang sudah kusam tidak terpelihara. Perawatan kamar yang kurang, karena beberapa benda di kamar mandi sudah berkarat dan berjamur. Lantai kamar mandi kurang bersih dan sudah keropos nampak tidak diperbaiki.

METODE
Penelitian ini berjenis penelitian assosiatif bentuk hubungan kasual melalui metode survei. Sugiyono (2009: 37) mangatakan "Hubungan kasual adalah hubungan yang bersifat sebab akibat". Jadi penelitian ini melibatkan dua variabel yaitu variabel independen (fasilitas kamar) dan dependen (kepuasan tamu).

Jenis data dalam penelitian ini adalah data primer dan data sekunder. Data Primer adalah data yang diperoleh langsung dari responden dengan menyebarkan angket kepada pengunjung yang menjadi sampel dalam penelitian. Sedangkan data sekunder adalah data diperoleh secara tidak lansung dari objek penelitian dengan memanfaatkan data yang sudah ada. Dalam penelitian ini data sekunder diperoleh dari pihak Basko Hotel Padang mengenai jumlah occupancy setahun terakhir. Teknik non probability sampling, yaitu metode sampling yang tidak memberi kesempatan atau peluang yang sama bagi setiap unsur atau populasi untuk dipilih menjadi sampel adalah metode yang digunakan dalam penelitian ini. Sedangkan jenis non probability sampling yang digunakan adalah insidental sampling, yaitu teknik sampling berdasarkan kebetulan yaitu siapa saja tamu domestik yang secara kebetulan bertemu dengan peneliti saat menyebar angket dapat digunakan sebagai sampel, bila dipandang orang yang kebetulan ditemui cocok sebagai sumber data.

\section{HASIL DAN PEMBAHASAN}

\section{Hasil}

1. Variabel Fasilitas Kamar

Dari hasil pengisian angket dengan jumlah pertanyaan 14 item, maka deskripsi data hasil penelitian sebagai berikut:

Tabel 1. Deskripsi Variabel Fasilitas Kamar

\begin{tabular}{|c|c|c|c|}
\hline Kategori & $\begin{array}{c}\text { Rentang } \\
\text { Interval }\end{array}$ & $\begin{array}{c}\text { Frekuen } \\
\text { si }\end{array}$ & $\%$ \\
\hline
\end{tabular}




\begin{tabular}{|l|c|c|c|}
\hline $\begin{array}{l}\text { Sangat } \\
\text { Baik }\end{array}$ & $3,26-4,00$ & 4 & 4 \\
\hline Baik & $2,51-3,25$ & 45 & 45 \\
\hline $\begin{array}{l}\text { Kurang } \\
\text { Baik }\end{array}$ & $\mathbf{1 , 7 6 - 2 , 5 0}$ & $\mathbf{4 9}$ & $\mathbf{4 9}$ \\
\hline $\begin{array}{l}\text { Tidak } \\
\text { Baik }\end{array}$ & $1,00-1,75$ & 2 & 2 \\
\hline \multicolumn{2}{|r|}{ Jumlah } & 100 & 100 \\
\hline
\end{tabular}

Variabel fasilitas kamar 49 (49\%) termasuk dalam kategori kurang baik.

a. Fasilitas kamar tidur

Dari hasil pengisian angket dengan jumlah pertanyaan 7 item, maka deskripsi data hasil penelitian sebagai berikut:

Tabel 2. Deskripsi Indikator Fasilitas Kamar Tidur

Indikator fasilitas kamar tidur $56 \%$ termasuk dalam kategori baik.

b. Fasilitas Kamar Mandi

Dari hasil pengisian angket dengan jumlah petanyaan 5 item, maka deskripsi data hasil penelitian sebagai berikut:

Tabel 3. Deskripsi Indikator Kamar Mandi

\begin{tabular}{|c|c|c|c|}
\hline Kategori & $\begin{array}{l}\text { Rentang } \\
\text { Interval }\end{array}$ & Frekuensi & $\%$ \\
\hline $\begin{array}{l}\text { Sangat } \\
\text { Baik }\end{array}$ & $3,26-4,00$ & 2 & 2 \\
\hline Baik & $2,51-3,25$ & 58 & 58 \\
\hline $\begin{array}{c}\text { Kurang } \\
\text { Baik }\end{array}$ & $1,76-2,50$ & 38 & 38 \\
\hline $\begin{array}{l}\text { Tidak } \\
\text { Baik }\end{array}$ & $1,00-1,75$ & 2 & 2 \\
\hline \multicolumn{2}{|c|}{ Jumlah } & 100 & 100 \\
\hline
\end{tabular}

Indikator fasilitas kamar 58\% termasuk dalam kategori baik.

c. Guest Supplies
Dari hasil pengisian angket dengan jumlah pertanyaan 2 item, maka deskripsi data hasil penelitian sebagai berikut:

Tabel 4. Deskripsi Indikator Guest Supplies

\begin{tabular}{|l|c|c|c|}
\hline Kategori & $\begin{array}{c}\text { Rentang } \\
\text { Interval }\end{array}$ & $\begin{array}{c}\text { Frekuens } \\
\mathbf{i}\end{array}$ & $\mathbf{\%}$ \\
\hline $\begin{array}{l}\text { Sangat } \\
\text { Baik }\end{array}$ & $3,26-4,00$ & 3 & 3 \\
\hline Baik & $2,51-3,25$ & 31 & 31 \\
\hline $\begin{array}{l}\text { Kurang } \\
\text { Baik }\end{array}$ & $\mathbf{1 , 7 6 - 2 , 5 0}$ & $\mathbf{6 4}$ & $\mathbf{6 4}$ \\
\hline $\begin{array}{l}\text { Tidak } \\
\text { Baik }\end{array}$ & $1,00-1,75$ & 2 & 2 \\
\hline \multicolumn{2}{|r|}{ Jumlah } & 100 & 100 \\
\hline
\end{tabular}

Indikator guest supplies $64 \%$ termasuk dalam kategori kurang baik.

2. Variabel Kepuasan Tamu

Dari hasil pengisian angket dengan jumlah pernyataan 16 item, maka deskripsi data hasil penelitian sebagai berikut:

\begin{tabular}{|l|c|c|c|}
\hline \multicolumn{1}{|c|}{ Kategori } & $\begin{array}{c}\text { Rentang } \\
\text { Interval }\end{array}$ & $\begin{array}{c}\text { Frekue } \\
\text { nsi }\end{array}$ & \% \\
\hline Sangat Baik & $3,26-4,00$ & 4 & 4 \\
\hline Baik & $\mathbf{2 , 5 1 - 3 , 2 5}$ & $\mathbf{5 6}$ & $\mathbf{5 6}$ \\
\hline Kurang Baik & $1,76-2,50$ & 39 & 39 \\
\hline Tidak Baik & $1,00-1,75$ & 1 & 1 \\
\hline \multicolumn{2}{|c|}{ Jumlah } & 100 & 100 \\
\hline
\end{tabular}

Tabel 5. Deskripsi Variabel Kepuasan Tamu

\begin{tabular}{|l|c|c|c|}
\hline Kategori & $\begin{array}{c}\text { Rentang } \\
\text { Interval }\end{array}$ & Frekuensi & \% \\
\hline $\begin{array}{l}\text { Sangat } \\
\text { Baik }\end{array}$ & $3,26-4,00$ & 2 & 2 \\
\hline Baik & $2,51-3,25$ & 41 & 41 \\
\hline $\begin{array}{l}\text { Kurang } \\
\text { Baik }\end{array}$ & $\mathbf{1 , 7 6 - 2 , 5 0}$ & $\mathbf{5 6}$ & $\mathbf{5 6}$ \\
\hline
\end{tabular}




\begin{tabular}{|l|c|c|c|}
\hline $\begin{array}{l}\text { Tidak } \\
\text { Baik }\end{array}$ & $1,00-1,75$ & 1 & 1 \\
\hline \multicolumn{2}{|c|}{ Jumlah } & 100 & 100 \\
\hline
\end{tabular}

Variabel kepuasan tamu 56\% termasuk dalam kategori kurang baik.

a. Tercapainya Harapan Tamu

Dari hasil pengisian angket dengan jumlah pernyataan 4 item, maka deskripsi data hasil penelitian sebagai berikut :

Tabel 6. Deskripsi Indikator Tercapainya HarapanTamu

\begin{tabular}{|l|c|c|c|}
\hline Kategori & $\begin{array}{c}\text { Rentang } \\
\text { Interval }\end{array}$ & Frekuensi & $\mathbf{\%}$ \\
\hline $\begin{array}{l}\text { Sangat } \\
\text { Baik }\end{array}$ & $3,26-4,00$ & 0 & 0 \\
\hline Baik & $\mathbf{2 , 5 1 - 3 , 2 5}$ & $\mathbf{5 0}$ & $\mathbf{5 0}$ \\
\hline $\begin{array}{l}\text { Kurang } \\
\text { Baik }\end{array}$ & $1,76-2,50$ & 49 & 49 \\
\hline Tidak Baik & $1,00-1,75$ & 1 & 1 \\
\hline \multicolumn{2}{|r|}{ Jumlah } & 100 & 100 \\
\hline
\end{tabular}

Indikator tercapainya harapan tamu 50\% termasuk dalam kategori baik.

b. Terpenuhinya Kebutuhan Tamu

Dari hasil pengisian angket dengan jumlah pernyataan 6 item, maka deskripsi data hasil penelitian sebagai berikut:

Tabel 7. Deskripsi Indikator Terpenuhinya Harapan Tamu

\begin{tabular}{|l|c|c|c|}
\hline Kategori & $\begin{array}{c}\text { Rentang } \\
\text { Interval }\end{array}$ & Frekuensi & $\mathbf{\%}$ \\
\hline $\begin{array}{l}\text { Sangat } \\
\text { Baik }\end{array}$ & $3,26-4,00$ & 1 & 1 \\
\hline Baik & $2,51-3,26$ & 27 & 27 \\
\hline $\begin{array}{l}\text { Kurang } \\
\text { Baik }\end{array}$ & $\mathbf{1 , 7 6 - 2 , 5 0}$ & $\mathbf{7 2}$ & $\mathbf{7 2}$ \\
\hline Tidak & $1,00-1,75$ & 0 & 0 \\
\hline
\end{tabular}

Baik

Jumlah

100

100

c. Tercapainya Keinginan Tamu

Dari hasil pengisian angket dengan jumlah pernyataan 2 item, maka deskripsi data hasil penelitian sebagai berikut:

Tabel 8. Deskripsi Indikator Tercapainya Keinginan Tamu

\begin{tabular}{|l|c|c|c|}
\hline Kategori & $\begin{array}{c}\text { Rentang } \\
\text { Interval }\end{array}$ & $\begin{array}{c}\text { Frekuen } \\
\text { si }\end{array}$ & \% \\
\hline $\begin{array}{l}\text { Sangat } \\
\text { Baik }\end{array}$ & $3,26-4,00$ & 2 & 2 \\
\hline Baik & $2,51-3,26$ & 26 & 26 \\
\hline $\begin{array}{l}\text { Kurang } \\
\text { Baik }\end{array}$ & $\mathbf{1 , 7 6 - 2 , 5 0}$ & $\mathbf{7 1}$ & $\mathbf{7 1}$ \\
\hline Tidak Baik & $1,00-1,75$ & 1 & 1 \\
\hline \multicolumn{2}{|r|}{ Jumlah } & 100 & 100 \\
\hline
\end{tabular}

Indikator tercapainya keinginan tamu $71 \%$ termasuk dalam kategori kurang baik.

d. Keinginan Memakai Produk Kembali

Dari hasil pengisian angket dengan jumlah peryataan 2 item, maka deskripsi data hasil penelitian sebagai barikut:

Tabel 9. Deskripsi Indikator Memakai Produk Kembali

\begin{tabular}{|l|c|c|c|}
\hline Kategori & $\begin{array}{c}\text { Rentang } \\
\text { Interval }\end{array}$ & Frekuensi & \% \\
\hline $\begin{array}{l}\text { Sangat } \\
\text { Baik }\end{array}$ & $3,26-4,00$ & 2 & 2 \\
\hline Baik & $2,51-3,25$ & 29 & 29 \\
\hline $\begin{array}{l}\text { Kurang } \\
\text { Baik }\end{array}$ & $\mathbf{1 , 7 6 - 2 , 5 0}$ & $\mathbf{6 8}$ & $\mathbf{6 8}$ \\
\hline Tidak baik & $1,00-1,75$ & 1 & 1 \\
\hline \multicolumn{2}{|c|}{ Jumlah } & 100 & 100 \\
\hline
\end{tabular}


Indikator keinginan memakai produk kembali $68 \%$ termasuk dalam kategori kurang baik.

e. Keinginan Untuk Merekomendasikan Kepada Orang Lain

Dari hasil pengisian angket dengan jumlah pernyataan 2 item, maka deskripsi data hasil penelitian sebagai berikut:

Tabel 10. Deskripsi Indikator Keinginan Untuk Merekomendasikan Kepada Orang Lain

\begin{tabular}{|l|c|c|c|}
\hline Kategori & $\begin{array}{c}\text { Rentang } \\
\text { Interval }\end{array}$ & Frekuensi & $\mathbf{\%}$ \\
\hline $\begin{array}{l}\text { Sangat } \\
\text { Baik }\end{array}$ & $3,26-4,00$ & 1 & 1 \\
\hline Baik & $2,51-3,25$ & 40 & 40 \\
\hline $\begin{array}{l}\text { Kurang } \\
\text { Baik }\end{array}$ & $\mathbf{1 , 7 6 - 2 , 5 0}$ & $\mathbf{5 7}$ & $\mathbf{5 7}$ \\
\hline $\begin{array}{l}\text { Tidak } \\
\text { Baik }\end{array}$ & $1,00-1,75$ & 2 & 2 \\
\hline \multicolumn{2}{|c|}{ Jumlah } & 100 & 100 \\
\hline
\end{tabular}

Indikator keinginan untuk
merekomendasikan kapada orang lain 57\% termasuk dalam kategori kurang baik.

3. Uji Persyaratan Analisis

a. Uji Normalitas

Untuk variabel fasilitas kamar Nilai Asym Sig adalah 0,148 dan pada variabel kepuasan tamu adalah 0,105 yang mana nilai tersebut $>$ dari 0,05 , sehingga data tersebut bisa dikatakan normal.

b. Uji Homogenitas

Hasil dari uji homogenitas adalah 0,133 yang mana nilai tesebut $>0,05$. Ini artinya taraf signifikan lebih rendah dari nilai signifikan data, jadi data dalam penelitian ini bersifat homogen.

c. Uji Linearitas
Hasil dari uji lineritas adalah 0,710 yang artinya adanya hubungan linear secara signifikan antara variabel fasilitas kamar (X) dan kepuasan tamu(Y) karena uji linearlitas besar dari 0,05.

4. Uji Hipotesis

\section{a. Uji Regresi Linear Sederhana}

Uji Hipotesis dilakukan untuk mengetahui seberapa besar pengaruh antara fasilitas kamar terhadap kepuasan tamu menginap di Basko Hotel Padang. Hipotesis dalam penelitian ini adalah:

Ha : Terdapat pengaruh fasilitas kamar terhadap kepuasan tamu menginap di Basko Hotel Padang.

Ho : Tidak terdapat pengaruh fasilitas kamar terhadap kepuasan tamu menginap di Basko Hotel Padang.

Tabel 11. Uji Regresi Linear Sederhana

\section{ANOVA $^{b}$}

\begin{tabular}{|c|c|c|c|c|c|}
\hline Model & $\begin{array}{l}\text { Sum of } \\
\text { Squares }\end{array}$ & $\mathrm{df}$ & $\begin{array}{l}\text { Mean } \\
\text { Square }\end{array}$ & $\mathrm{F}$ & Sig. \\
\hline $\begin{array}{ll}1 & \text { Regressio } \\
\mathrm{n}\end{array}$ & 911.181 & 1 & $\begin{array}{r}911.18 \\
1\end{array}$ & $\begin{array}{r}58.94 \\
8\end{array}$ & .000 \\
\hline Residual & $\begin{array}{r}1514.81 \\
9\end{array}$ & $\begin{array}{l}9 \\
8\end{array}$ & 15.457 & & \\
\hline Total & $\begin{array}{r}2426.00 \\
0\end{array}$ & $\begin{array}{l}9 \\
9\end{array}$ & & & \\
\hline
\end{tabular}

a. Prodictors:

(Constant), Fasilitas

Kamar

b. Dependent Variabel:

Kepuasan Tamu

Dari uji regresi linier didapatkan nilai $\mathrm{F}$ hitung 58,948 dengan sig. $0,00<0,05$ yang berarti variabel fasilitas kamar (X) bisa menjelaskan variabel kepuasan tamu (Y) dengan signifikan. Maka bisa dikatan kan 
variabel fasilitas kamar mempengaruhi kepuasan tamu, dengan itu Ha diterima dan Ho ditolak.

Tabel 12. Koefisien Regresi

\section{Coefficients $^{\mathrm{a}}$}

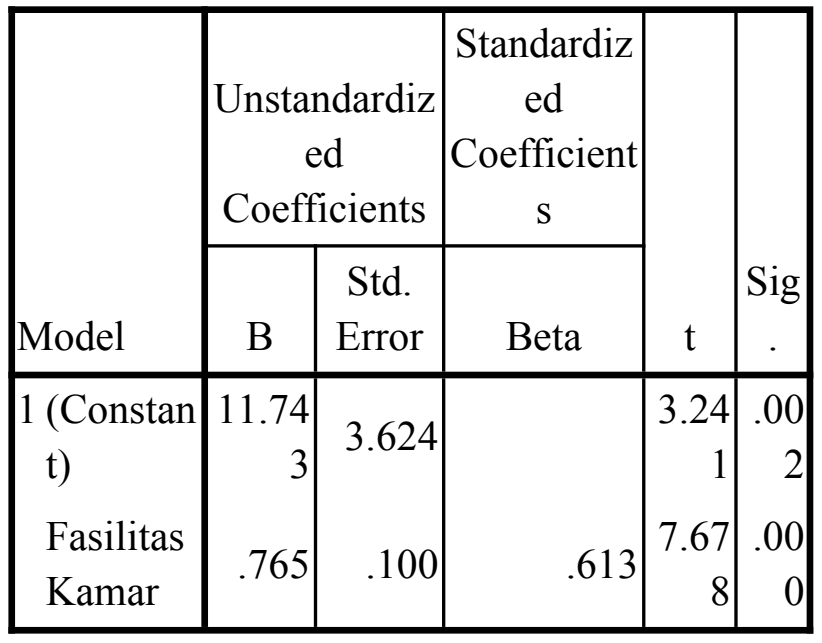

Didapat hasil koefisien sebesar 0,765 dengan nilai t hitung 7,678 pada sig. $0,00<$ 0,05. Jadi setiap peningkatan sebesar 1 satuan variabel fasilitas kamar dapat meningkatkan 0,765 satuan kepuasan tamu.

Uji ini dilakukan untuk mengetahui seberapa besar pengaruh variabel fasilitas kamar terhadap variabel kepuasan tamu.

Tabel 13. R Square

\begin{tabular}{|l|l|r|r|r|}
\multicolumn{1}{|c|}{ Model Summary $^{\mathbf{b}}$} \\
\hline Model & $\mathrm{R}$ & $\begin{array}{c}\mathrm{R} \\
\text { Square }\end{array}$ & $\begin{array}{c}\text { Adjusted } \\
\text { R Square }\end{array}$ & $\begin{array}{c}\text { Std. Error } \\
\text { of the } \\
\text { Estimate }\end{array}$ \\
\hline 1 & $.613^{\mathrm{a}}$ & .376 & .369 & 3.932 \\
\hline
\end{tabular}

a. Predictors: (Constant), Fasilitas

Kamar

b. Dependent Variable: Kepuasan

Tamu

Berdasarkan tabel di atas diperoleh nilai $\mathrm{R}$ Square 0,376 Artinya pengaruh variabel fasilitas kamar (X) terhadap variabel kepuasan tamu (Y) adalah sebesar 37,6\%. Sedangkan $61,3 \%$ dipengaruhi oleh faktor lain.

\section{Pembahasan}

\section{Fasilitas Kamar}

Berdasarkan hasil penelitian secara umum fasilitas kamar di Basko Hotel Padang, sebanyak 4 (4\%) menunjukkan kategori sangat baik, 45 (45\%) menunjukan kategori baik, 49 (49\%) menunjukkan kategori kurang baik dan 2 (2\%) menunjukkan kategori tidak baik. Artinya Dari hasil di atas, menggambarkan bahwa fasilitas di Basko Hotel Padang belum mencapai tingkat yang sangat baik, sehingga perlu ditingkatkan lagi. Pihak hotel harus melakukan perawatan secara rutin dan mengganti fasilitas-fasilitas yang telah rusak agar tamu merasa nyaman selama menginap di hotel. Sulastiyono (2011: 28) mengatakan, "Fasilitas adalah penyediaan perlengkapan-perlengkapan fisik untuk memberikan kemudahan kepada para tamu dalam melaksanakan kegiatannya, sehingga kebutuhan-kebutuhan tamu dapat terpenuhi selama berada di Hotel". Oleh karena itu, pihak hotel harus meningkatkan, mengganti dan melengkapi penilaian tamu terbanyak masuk dalam kategori kurang baik (49\%), dari hasil penelitian ini pihak hotel harus memperhatikan dan meningkatkan fasilitas kamar agar tamu marasa puas selama menginap di hotel. fasilitas kamar agar memberikan kemudahan kapada tamu dalam melaksanakan kegiatannya.

2. Kepuasan Tamu

Penelitian ini telah menemukan gambaran kepuasan tamu yang menginap di Basko Hotel Padang. Berdasarkan 100 responden untuk variabel kepuasan tamu dapat dikelompokkan sebagai berikut: 
sebanyak $2(2 \%)$ menunjukkan kategori sangat baik, 41 (41\%) menunjukan kategori baik, 56 (56\%) menunjukkan kategori kurang baik dan 1 (1\%) menunjukkan kategori tidak baik.

Secara keseluruhan variabel kepuasan tamu (Y) di Basko Hotel Padang tergolong kategori kurang baik.

Menurut Oliver (dalam Supranto, 2006: 233), "Kepuasan adalah tingkat perasaan seseorang setelah membandingkan kinerja/hasil yang dirasakannya dengan harapannya". Kotler dan Keller (dalam Irawan dan Japarianto, 2013: 2-3) menyatakan bahwa, "Kepuasan adalah perasaan senang atau kecewa seseorang yang muncul setelah membandingkan kinerja atau hasil dari sebuah produk yang dipikirkan terhadap kinerja atau hasil yang diharapkan". Dari pendapat tersebuk bisa disimpulkan bahwa kepuasan tamu akan menunjukan perasaan puas atau tidak puasnya seorang tamu atas fasilitas yang dirasakan dengan membandingkan harapan sebelum dengan sesudah menikmati fasilitas yang ada.

\section{PENUTUP}

\section{Simpulan}

1. Fasilitas Kamar di Basko Hotel Padang termasuk kedalam kategori yang kurang baik.

2. Kepuasan Tamu di Basko Hotel Padang termasuk kategori yang kurang Puas.

3. Adanya pengaruh antara variabel fasilitas kamar (X) terhadap variabel kepuasan tamu (Y) adalah sebesar 37,6\%. Sedangkan $61,3 \%$ dipengaruhi oleh faktor lain.

\section{Saran}

Diharapkan pihak hotel lebih meningkatkan lagi dan memperbaharui fasilitas kamar terutama fasilitas kamar tidur (tempat tidur, AC, lampu penerang, linen dan lain-lain) dan fasilitas kamar mandi (bath tub, shower, towel, wash basin dan lain-lain) sehingga fasilitas kamar menjadi lebih baik.

Bagi mahasiswa pariwisata diharapkan penelitian ini menjadi bahan pembelajaran untuk menambah ilmu pengetahuan dan wawasan, dalam melakukan penelitian.

\section{DAFTAR PUSTAKA}

Kotler, Philip. 2000. Manajemen Pemasaran Perspektif Asia. Jakarta: PT Prenhallindo.

Rumekso. 2001. Housekeeping Hotel.

Yogyakarta: CV Andy offset..

Setiawati. 2009. Optimalisasi peran wanita di keluarga dalam membentuk sumber daya manusia. Diakses 01 Agustus 2017.

http://buletinlitbang.dephan.go.id.

Sugiyono. 2009. Metode Penelitian. CV Alfabeta: Bandung

Sulastiyono. 2011. Manajemen

Penyelenggaraan Hotel. Seri

Manajemen Usaha Jasa Sarana

Pariwisata Dan Akomodasi. Alfabeta, $\mathrm{CV}$.

Supranto, Johanes. 2006. Pengukuran Tingkat Kepuasan Pelanggan: Untuk Menaikan Pangsa Pasar. Jakarta: Rineka Cipta. 